\title{
Remediation of soil co-contaminated with pyrene and cadmium by growing maize (Zea mays L.)
}

\author{
H. Zhang; *Z. Dang; L. C. Zheng; X. Y. Yi \\ School of Environmental Science and Engineering, South China University of Technology, Guangzhou Higher \\ Education Mega Center, Guangzhou 510006, P. R. China \\ Received 8 October 2008; $\quad$ revised 21 January 2009; accepted 25 February 2009; available online 1 March 2009
}

\begin{abstract}
Sites co-contaminated with organic and metal pollutants are common and considered to be a more complex problem as the two components often causes a synergistic effect on cytotoxicity. Phytoremediation has been proposed as a cost-effective technology for treating heavy metal or organic contamination and may be suitable for remediation of co-contaminated soil. This study investigated the concurrent removal of pyrene and cadmium in cocontaminated soil by growing maize in a pot experiment. At the end of 60 day culture, pyrene in spiked soil diminished significantly, accounting for $21-31 \%$ of the initial extractable concentration in unplanted soil and $12-27 \%$ in planted soil. With the increment of cadmium level, the residual pyrene both in unplanted and planted soil tended to increase. Although the presence of cadmium increased the accumulation of pyrene in maize, plant accumulation only account for less than $0.30 \%$ of the total amount of the dissipated pyrene in vegetated soils. It implied that plant-promoted microbial biodegradation was the predominant contribution to the plant-enhanced dissipation of pyrene in co-contaminated soil. Unlike pyrene, heavy metal cadmium cannot be degraded. It was observed that maize can concurrently removed about on the average $0.70 \%$ of the total cadmium amount in soil by plant uptake, but cadmium phytoextraction would be inhibited under contamination of pyrene. Maize CT38 can normally grow in the co-contaminated soil with high level cadmium and pyrene and can effectively remedy the sites co-contaminated with these two types of contamination, which suggest the possibility of simultaneous phytoremediation of two different contaminant types.
\end{abstract}

Keywords: Heavy metal, polycyclic aromatic hydrocarbons, maize, phytoextraction

\section{INTRODUCTION}

It was reported that forty percent of hazardous waste sites on the U. S. Environmental Protection Agency's national priority list (NPL) are co-contaminated with organic and heavy metal pollutants (Benin et al., 1999; Cheng, 2003; Sandrin and Maier, 2002). Common heavy metal contaminants include arsenic, cadmium, chromium, copper, lead, mercury, nickel and zinc, which present numerous health dangers to higher organisms and are also known to decrease plant growth, ground cover and have a negative impact on soil microflora (Garbisu and Alkorta, 2001; McGrath et al., 2001). Common organic pollutants at these sites include petroleum hydrocarbons (TPHs) and polycyclic aromatic hydrocarbons (PAHs) from exploration and consumption of fossil fuel, polychlorinated biphenyls (PCBs) widely used in industrial processes and other

《*Corresponding Author Email: chzdang@scut.edu.cn

Tel.: +86 20 39380522; Fax: +86 2022236133 chlorinated aromatics. One in situ decontamination approach showing promise for addressing both organic and inorganic contaminants is phytoremediation -the attenuation of pollution through the use of plantswhich impose minimal environmental disturbance and offer economic, agronomic and societal benefits.

Up to the present time, central to the remediation field for heavy metals is the screening of hyperaccumulative plants for their specific capabilities in regard to metal accumulation and resistance, as well as their impact on rhizosphere microflora diversity, density and metabolic activity (Baker et al., 1994; Blaylock et al., 1997). Although there are roughly 400 known species of plants characterized as metal hyperaccumulators (McIntyre and Glennis, 1997), in-situ, successful application of hyperaccumulator has been limited because of their low biomass and specific growth needs. Over the last few years, plant-enhanced 
remediation of soil organic contaminants has also been investigated since it is known that plant exudates are a significant source of organic nutrients and inorganic compounds. In terms of energy, the amount of exudates can be equivalent to $10-20 \%$ of the plant's annual photosynthesis (Schnoor et al., 1995). Plants may contribute to the dissipation of organics by plant uptake and accumulation, increase in microbial numbers, improvement of physical and chemical soil conditions and adsorption of pollutants in the rhizosphere. However, the impact of each process has not been clearly elucidated (Ling and Gao, 2004).

In heavy metal-organic pollutant combined systems, previous studies have shown that biodegradation of organic contaminants is often severely inhibited by toxic metals, such as cadmium (Maslin and Maier, 2000; Said and Lewis, 1991). In some cases, however, the addition of metals has been observed to stimulate microbial activity. Kuo and Genthner (1996) reported that the addition of some metals at low levels stimulated biodegradation. Copper and cadmium (both at $0.01 \mathrm{mg}$ total metal/L) increased the benzoate biodegradation rate by $185 \%$ and the 2-chlorophenol biodegradation rate by $168 \%$. Lin et al. (2006) found that the higher PCP dissipation in soil spiked with $50 \mathrm{mg} / \mathrm{kg}$ PCP in the presence of $\mathrm{Cu}$. In copper co-contaminated soil with an initial PCP concentration of $100 \mathrm{mg} / \mathrm{kg}$, however, both plant growth and microbial activity were inhibited with the increment of soil $\mathrm{Cu}$ level. The efficiency and mechanisms of phytoremediation of organic pollutants co-existing with heavy metals is complex and quite different from that in the single-pollutant system. Therefore, a more thorough understanding of the mechanisms by which metals affect the dissipation of organic pollutants in the planted soils is needed.

This study was conducted to investigate the influence of contamination on the growth maize and the fate of pollutants in soil and plant. Pyrene was used as the model organic in this study because it represents a class of organic compounds, polyaromatic hydrocarbons, with carcinogenic potential that is present at many superfund sites. Cadmium was chosen as the metal as it is the second most common metal found at superfund sites and is one of the ten high-priority pollutants. Screening of effective plant species was performed prior to this study. The experiment continued to 60 days (from March 1st, 2008 to April 30th, 2008) in the greenhouse at South China University of Technology, Guangzhou, China. A species of maize CT38 was chosen for its ability to extract heavy- metals, remove PAH and having a high-biomass when grown on the tested soils. In the previous work (Zhou et al., 2005; 2007), it was found that maize CT38 (Zea Mays L.) could normally grow and effectively extract metals in multi-metal (Cu, Cd, $\mathrm{Pb}$ and $\mathrm{Zn}$ ) contaminated soils from Daobaoshan mine, located in northern Guangdong Province,China.

\section{MATERIALS AND METHODS}

\section{Soil treatment}

Soil was collected from the top layer $(0-20 \mathrm{~cm})$ of an agricultural field with $\mathrm{pH} 6.42,1.63 \%$ organic matter, originally free of pyrene and $0.13 \mathrm{mg} \mathrm{Cd} / \mathrm{kg}$ soil in Zengcheng county, Guangdong Province, China. The soil was air-dried and sieved through a $3 \mathrm{~mm}$ mesh. The levels of cadmium and pyrene added into the soil were 0 , 2.0, $4.5 \mathrm{mg} \mathrm{Cd} / \mathrm{kg}$ soil and $0,10,50,100 \mathrm{mg}$ pyrene/kg soil. Briefly, the bulk soil was first mixed thoroughly with cadmium (as $\mathrm{CdCl}_{2}$ ) in an aqueous solution and incubated at a moisture condition for 2 weeks. Subsamples containing pyrene was prepared with the above material. Soils were spiked with a mixture of high purity pyrene in acetone. After the acetone had evaporated, the spiked soils were then sieved again through a $3 \mathrm{~mm}$ mesh to ensure homogeneity and stored for use. Treated soils were then packed into pots (4 kg dry weigh soil per pot) and placed in a glass greenhouse at $60 \%$ of the soil water holding capacity.

\section{Experimental design}

Pregerminated seeds of maize CT38 (Zea mays L.) were sown in each pot. The seedlings were thinned 5-7 days after emergence to leave one plant per pot. Each treatment was repeated in triplicate and the treated pots were randomized in the greenhouse and places exchanged every second day. Soils were carefully watered as needed and fertilized with NPK fertilize mixture ( $1 \mathrm{~g} / \mathrm{kg}$ of soil) containing $\mathrm{N}: \mathrm{P}_{2} \mathrm{O}_{5}: \mathrm{K}_{2} \mathrm{O}=1: 0.35: 0.8$.

\section{Sampling and analysis}

Pots were left without watering for 1 day prior to harvests (60 days after seeding). At harvest, shoots were cut at the soil surface, dried and weighed. The upper 2-5 mm of soil in each pot was discarded. By further gently crushing the soil and shaking the roots, the portion of soil obtained in this manner was also discarded, which account for 70-80 \% of soil mass. Soil obtained by continued vigorous rubbing and 
shaking of the root system was classified as strongly adhering soils (10-15\% of the soil) or planted soil. Unplanted soil was obtained in a similar way. Soils and plants for analysis of chemical or enzymatic activity were stored at $-20^{\circ} \mathrm{C}$ and $4{ }^{\circ} \mathrm{C}$, respectively.

The procedure used to extract PAHs was a modification of those of Kipopoulou et al. (1999) and Gao and Zhu (2004). Sample preparation included homogeneous mixing of $2 \mathrm{~g}$ of soil sample with anhydrous $\mathrm{Na}_{2} \mathrm{SO}_{4}$ to remove moisture and ultrasonication in $10 \mathrm{~mL}$ of dichloromethane for $1 \mathrm{~h}$ followed by centrifugation. Then $3 \mathrm{~mL}$ of supernatant was filtered through $2 \mathrm{~g}$ of silica gel column with $11 \mathrm{~mL}$ 1:1 elution of hexane and dichloromethane. The solvent fractions were then evaporated and exchanged by methanol with a final volume of $2 \mathrm{~mL}$. Plant samples were extracted by ultrasonication for $1 \mathrm{~h}$ in enough $1: 1$ solution of acetone and hexane. The solvent fractions passed through an anhydrous $\mathrm{Na}_{2} \mathrm{SO}_{4}$ column with elution of 1:1 acetone and hexane. The solvents were then evaporated and exchanged to $2 \mathrm{~mL}$ hexane, followed by filtration through $2 \mathrm{~g}$ of silica gel column with $11 \mathrm{~mL}$ of $1: 1$ elution of hexane and dichloromethane. The samples were then evaporated and exchanged by methanol with a final volume of $2 \mathrm{~mL}$. After filtration through $0.22 \mu \mathrm{m}$ filter units, the treated soil and plant tissue extracts were analyzed with a high-performance liquid chromatograph fitted with a $4.6 \times 250 \mathrm{~mm}$ reverse phase $\mathrm{C} 18$ column using methanol-water $(85: 15)$ as the mobile phase at a flow rate of $1 \mathrm{~mL} / \mathrm{min}$. Chromatography was performed at $30^{\circ} \mathrm{C}$. Pyrene was detected at $238 \mathrm{~nm}$.

The soil samples were ground into a fine powder and sieved through a 150-mesh stainless-steel screen. Soil samples were wet-digested with a mixture of $\mathrm{HNO}_{3}-$ $\mathrm{HClO}_{4}$-HF acids. The selective sequential extraction procedures developed by Tessier et al., (1979) was used to study the chemical forms of heavy metal Cd in soil. Plant samples were digested using a mixture of $\mathrm{HNO}_{3}-$ $\mathrm{HClO}_{4}-\mathrm{HCl}$ acids. Inductively coupled plasma mass spectrometry (ICP-MS, Aligent7500A) was employed to analyze the solutions for concentrations of heavy metals.

\section{Data processing}

Results are presented as the average of three replicates. Statistical analyses were carried out using analysis of variance (ANOVA) or paired $t$-tests. The level of statistical significance is represented by * for $p<0.05$, ** for $p<0.01$ and NS for not significant.

\section{RESULTS AND DISCUSSION}

\section{Growth response}

At the end of 60 days of growth, despite a reduction in dry weight of root and shoot grown on some of the polluted soils, plants formed dense root systems and luxuriant aerial growth in the spiked soils. Roots and shoots biomass were affected by the pyrene and cadmium contamination (Fig. 1). For example, the dry weight of root and shoot grown on unspiked soils (A1) is 3.12 and $12.95 \mathrm{~g} / \mathrm{pot}$, respectively. With increase in pyrene and cadmium level, it was observed that the dry weight of root and shoot grown on the $50 \mathrm{mg} / \mathrm{kg}$ pyrene and $2.0 \mathrm{mg} / \mathrm{kg}$ cadmium treatment soils (B3) was 2.80 and $12.76 \mathrm{~g} /$ pot, respectively and it was 2.54 and 12.10 $\mathrm{g} /$ pot on the $100 \mathrm{mg} / \mathrm{kg}$ pyrene and 4.5 cadmium treatment soils (C4), respectively. There was a slight but non-significant $(p<0.05)$ decrease in roots and shoots dry weights in the pyrene spiked soils compared with that for the unspiked soils. However, a more significant decrease in roots and shoots dry weights was observed in the cadmium spiked soils. Pyrene cocontamination slightly decreased the roots dry weights further with increasing concentration of pyrene in co-contaminated soil, which suggests that pyrene contamination could exert synergistic toxic effects on plant growth. These results were different to that of Lin et al. (2006), who reported that with the initial concentration of $50 \mathrm{mg} / \mathrm{kg}$ PCP, no outward signs of phytotoxicity or even better growth for ryegrass and radish was shown with the increment of soil $\mathrm{Cu}$ level. Chekol et al. (2004) found that PCB spiking (100 $\mathrm{mg} / \mathrm{kg}$ ) of soil did not significantly affect the biomass of any tested grass species or the shoot weights of flat pea and sericea lespedeza. Perhaps plant species and the characteristics of pollutants cause different growth response of plants to organic or organic-heavy metal contamination.

\section{The dissipation of soil pyrene}

Pyrene both in planted and unplanted soil was greatly decreased at the end of the 60 day experiment, accounting for $21-31 \%$ of the initial extractable concentration in unplanted soil and $12-27 \%$ in planted soil. As shown in Fig. 2, the extractable pyrene in the planted soil was significantly lower than that in the unplanted, which confirmed the beneficial effect of vegetation. Fig. 2 also shows that the residual 
concentration of pyrene in pyrene-cadmium co-contaminated soils was also lower in planted soil than that in unplanted soil, which was in agreement with the findings of sole pyrene pollution. For example, it was observed that the extractable pyrene in the co-contaminated soil (B2-B4) was 1.55, 9.32, 21.80 $\mathrm{mg} / \mathrm{kg}$ in the planted soils where $10,50,100 \mathrm{mg} / \mathrm{kg}$ pyrene had been added respectively it was 2.47, 12.97, 27.09 $\mathrm{mg} / \mathrm{kg}$, respectively, in unplanted soil. Maize enhanced the remediation of soil pyrene contamination in both sole pyrene pollution and pyrene-cadmium co-contaminated soil.

The enhanced dissipation of persistent organic pollutants in soils by plants has been widely researched and could be attributed to the phenomena such as: (a) increased microbial activity in the rhizosphere soil. He et al. (2005) reported that the largest microbial biomass carbon was found at each PCP concentration treatment in the near-rhizosphere soils, especially at the 1-3 mm sampling zones. The increased microbial biomass is primarily due to the presence of plant exudates and sloughed biomass that serve as sources of energy, C, N, or growth factors; (b) plant uptake. Though plant uptake might be minimal as reported by He et al. (2005) and Nakamura et al. (2004); (c) degradation mediated by the enzymes secreted by plants in the root zone. Kaimi et al. (2006) found that the number of aerobic bacteria and the amount of soil dehydrogenase activity in planted soil were higher than that in unplanted soil and also showed a correlation with the growth of roots. The dissipation rate of diesel oil showed a correlation with soil dehydrogenase activity in both planted and unplanted soil.

Contrasting the pyrene-alone pollution and pyrenecadmium compound contamination indicated that, whether or not maize was planted, the residual pyrene in soil tended to increase with increased cadmium level. Fig. 3 shows the effect of cadmium on the pyrene dissipation in the planted soil. For example, the residual extractable pyrene was $1.12,7.39,17.45 \mathrm{mg} / \mathrm{kg}$ in the pyrene-alone contaminated planted soils with the treatment of $10,50,100 \mathrm{mg} / \mathrm{kg}$ pyrene, respectively. With increased cadmium level, it was observed that the extractable pyrene in the $2.0 \mathrm{mg} / \mathrm{kg}$ cadmium treatment soils was $1.55,9.32,21.80$, respectively and $1.86,10.90,26.38 \mathrm{mg} / \mathrm{kg}$ in the $4.5 \mathrm{mg} / \mathrm{kg}$ cadmium treatment soils.

Phytoremediation of organics is primarily based on the beneficial effects of roots on biodegradation. The increase residual concentration of pyrene in the presence of cadmium was probably attributed to changes in microbial composition, microbial activity

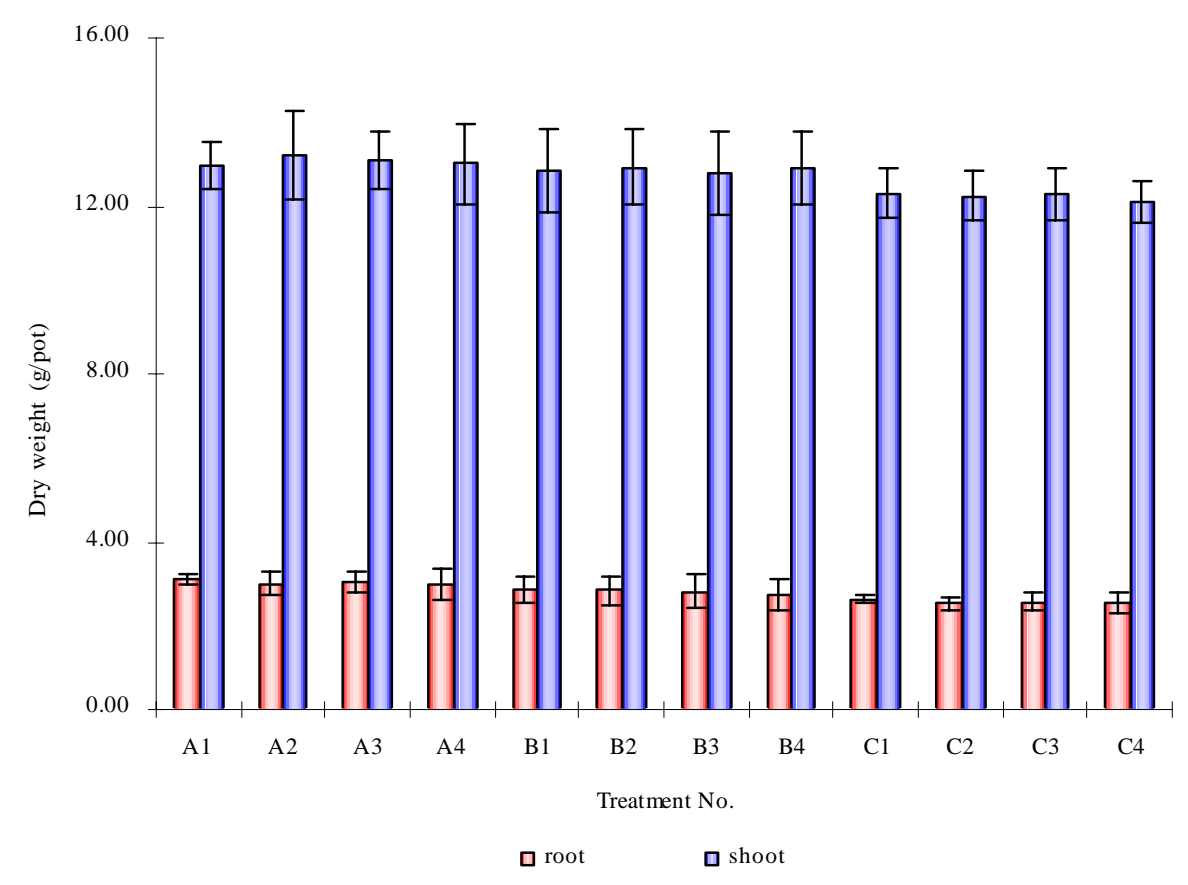

Fig. 1: Plant dry weight of maize as affected by the contamination of pyrene and cadmium 


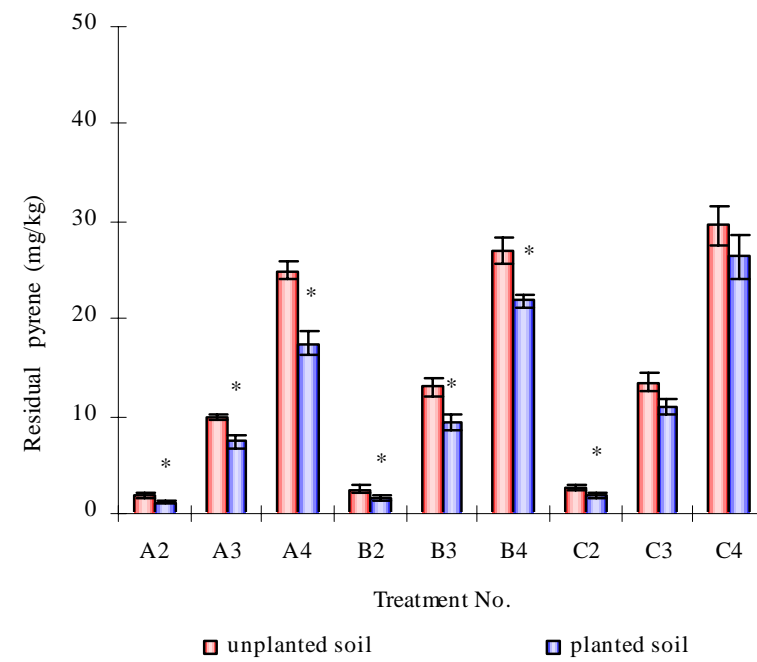

Fig.2: Residual concentraion of pyrene in soils (* indicated significant difference between unplanted and planted treantement)

and root physiology. Said and Lewis (1991) studied the quantitative effects of metals on microbial degradation of organic chemicals. Biodegradation inhibition of a benchmark chemical, 2, 4-dichloro-phenoxyacetic acid methyl ester (2, 4-DME) was used to quantify the inhibitory effects of heavy metals on aerobic microbial degradation rates of organic chemicals. Kuo and Genthner (1996) reported that metals adversely affecting degraders in a consortium. Additional of low levels of metals (0.1-2.0 mg total metal/L) lengthened the acclimation period and decreased dechlorination and biodegradation rates. It may be that cadmium toxicity inhibited the activity of pyrene-degrading microorganisms in co-contaminated sites. Metals also affected non-degradation consortium members that play a vital but indirect role in the degradation process. Similarly, this research group also found a significant decrease in microbial biomass in cadmium polluted soil (Zhang et al., 2007). In this experiment, the decreased microbial biomass was suggested as the reason for the increased pyrene residual. As known, changes in quality and quantity of root exudates would influence the degradation of xenobiotics, which was a microbially mediated process. The modified composition of root exudates under Cd stress might cause the decreased bioavailability of pyrene with formation of bound pyrene-organic matter which can be extracted by solvent. Olson et al. (2003) proposed that differences

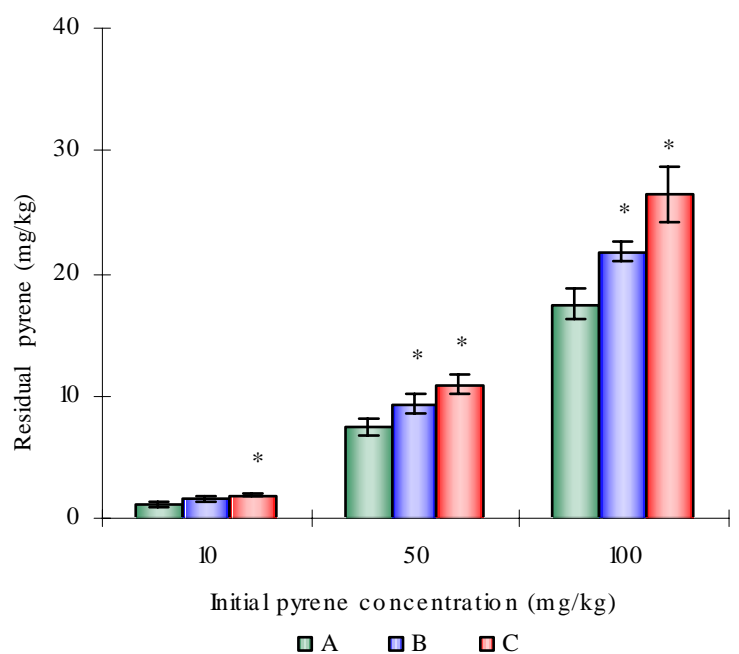

Fig.3: Residual concentration of pyrene in planted soils as affected by co-contamination of cadmium.

(*indicate significant different between A and cadmium treatment)

in the quantity and quality of nutrients released by root exudation and root mortality likely lead to variable and potentially opposing effects on microbial PAH degradation.

In this experiment, although the remediation of soil pyrene was enhanced in the presence of vegetation, a phenomenon was also observed: In the presence of a high concentration of cadmium ( $4.5 \mathrm{mg} / \mathrm{kg})$, there was no significant difference in the pyrene concentration between the planted soil and unplanted soil with the initial pyrene concentration of 50 and $100 \mathrm{mg} / \mathrm{kg}$ (as shown in Fig. 2). These results were similar to that of Lin et al. (2008). They observed that in the presence of a high concentration of $\mathrm{Cu}$ (> $200 \mathrm{mg} / \mathrm{kg}$ ), the pyrene residual was even higher in the planted soil than in the non-planted soil. The presence of mass flow and the lowered biodegradation for pyrene in the high level cadmium contamination were probably responsible for the small difference between the planted soil and unplanted cadmium-contaminated soil. Plant water uptake induced a mass flow of pyrene towards the root zone of enhanced microbial activity and conditions that favor pyrene dissipation. This explanation can be supported by the results of Liste and Alexander (2000). They suggested that PAH mobilization under plants has occurred because as much as $205 \%$ more butanolextractable pyrene was detected in a sterile fescue rhizosphere than in unplanted soil. When the mass 
flow occurred in the high cadmium co-contaminated planted soil, with pyrene flowing toward the root zone of the maize, the larger residual pyrene existed in the strongly adhering soils or planted soil. Because a high cadmium level inhibited the biodegradation of pyrene, the residual pyrene carried by mass flow in the rhizosphere or planted soil may be similar to that in unplanted soil or even higher. Lin et al. (2006) also found that the less difference of PCP residue between strongly and loosely adhering soil in $\mathrm{Cu}$ co-contaminated soils. The impact of metals on the biodegradation of organic pollutants was not only due to the metal concentrations and type, but also the content of the organic pollutants, indicating that the mechanisms by which metals inhibited biodegradation varied with the composition and complexity of the system under study and included both physiological and ecological components. Cadmium is one of the most toxic heavy metal pollutants, and the negative effect of $\mathrm{Cd}$ on the dissipation of organic pollutants in co-contaminated soils should be fully considered.

\section{Plant uptake and accumulation of pyrene}

Pyrene contents in the roots and shoots of maize, at the end of the 60 day experiment, as a function of the residual pyrene concentration in soil, are listed in Table 1. These results indicate that the accumulation of pyrene in roots and shoots increased consistently with an increment in the soil residual pyrene concentration. However, the concentrations of pyrene in shoots were statistically far lower than in roots. Concentrations of pyrene in roots grown in unspiked control soil were not detectable. But it was notable that even when shoots were grown in unspiked control soil, accumulation of pyrene was detected in the shoots (Table 1). The concentrations of pyrene in shoots grown in unspiked control soil A1 were $0.73 \mathrm{mg} / \mathrm{kg}$, which can only have derived from shoot uptake and accumulation from the atmosphere, probably through the retention of the vapor phase of pyrene on the waxy leaf cuticle (Polder et al., 1995; Trapp et al., 1990). This indicates that the shoot uptake of pyrene from the ambient air, possibly originally volatilized from the soils, was a pathway for pyrene intake by the above-ground parts of vegetables. Thus, the pyrene in shoots grown in spiked soil should be approximately the sum of the accumulation from air (denoted as the concentrations of pyrene in plant shoot grown in soil A1) and that translocated from roots (Schroll et al., 1994).
Atmospheric deposition is common for semivolatile organic chemicals in field conditions.

Although shoots apparently accumulated pyrene from air, the concentrations of pyrene in shoots grown in spiked soils were much larger than the shoot uptake and accumulation of pyrene in the unspiked control soil A1 (Table 1). This demonstrated that the translocation of pyrene from roots to shoots was much more significant than the deposition of pyrene onto maize from the atmosphere. According to the calculation method of Schroll et al. (1994), at the uptake pathway for organic chemicals from soils of agricultural plant, an average of $90 \%$ of the pyrene in shoots was translocated from roots. Since pyrene in the roots of maize grown in unspiked control soil A1 was not detectable, pyrene accumulated by shoots from the atmosphere were not transported to roots in any significant amount. These chemicals, when found in roots grown in various spiked soils, are derived from root uptake and accumulation.

It was observed that the uptake of pyrene in maize grown in soils contaminated with pyrene and cadmium was higher than that in soil co-contaminated with pyrene alone by $10.3 \%-35.1 \%$ in roots and $5.9 \%-26.5$ $\%$ in shoots. As mentioned above, for the same initial concentration of pyrene in soils, the residual concentrations of pyrene in polluted soils were higher than those in pyrene-only polluted soils because of the presence of cadmium. The accumulation of pyrene in maize from soil tended to increase with the level of their soil pyrene concentration, thus the greater accumulation of pyrene in maize appeared in soils cocontaminated with pyrene and cadmium. In this experiment, although the presence of cadmium stimulated the accumulation of pyrene in the roots and shoots of maize, the direct accumulation of pyrene in maize from spiked soils was always less than 282 $\mu \mathrm{g} /$ pot, which is less than $0.3 \%$ of the total dissipation of pyrene in the presence of vegetation. In contrast, plant-promoted biodegradation was the predominant contribution to the plant-enhanced dissipation of soil pyrene in the cadmium contamination.

\section{Plant uptake and accumulation of cadmium}

Bioremediation of inorganic contaminants such as heavy metals is more difficult than that of organic contaminants. The reason is partly due to the fact that microorganisms can degrade organic contaminants by oxidizing them to carbon dioxide, whereas metals by 
their nature are not biodegradable and microorganisms can only change the speciation of metal contaminants (Lovley and Coates, 1997; Pascale and Raina, 2000).

Fig. 4 showed the changes of percentage of cadmium fractions in unplanted and planted soil. It was clear that the percentage of exchangeable form $\mathrm{Cd}$ significantly decreased in the planted soil after 60 days culture. For phytoremediation occurence, Cd must be bioavailable (ready to be absorbed by roots). As known, the exchangeable form $\mathrm{Cd}$ is easily absorbed by plant. In the presence of vegetation, the exchangeable form Cd was partly removed by plant uptake that accompanied with the intake of nutrition. It is also observed that there was slightly but no-significant increase of the percentage of Fe/Mn oxides form Cd, carbonate form $\mathrm{Cd}$ and organic form $\mathrm{Cd}$ in planted soil compared with that in unplanted soil. The percentage of residual form Cd significantly increased in planted soil. A possible explanation could be the exchangeable form Cd in planted soil was the predominant species for Cd uptake by plant. As the phytoextraction of $\mathrm{Cd}$ by maize, the percentage of exchangeable form $\mathrm{Cd}$ decreased in the planted soil. Besides, plant root exudates and rhizosphere microorganisms accelerated the stability process of added Cd in soils, which might make the exchangeable form transform to other relatively stable forms such as organic form and residual form and might help reduce the harm of Cd to soil and water environment. There was no significant difference between the Cd sole-polluted soil and pyrene cocontaminated soil as comparing the percentage of $\mathrm{Cd}$ fractions.

Decontamination of Cd from contaminated soils in this system requires the removal of $\mathrm{Cd}$ by plants. Table 2 was the Cd concentration and accumulation in maize after 60 days culture. In the absence of pyrene, shoot and root Cd concentrations in maize increased with increasing soil Cd level. The ratio of shoot to root, however, decreased from 0.50 in control soil to 0.35 , 0.32 in $2.0,4.5 \mathrm{mg} \mathrm{Cd} / \mathrm{kg}$ soil, respectively, which also suggested the root acquisition of $\mathrm{Cd}$ intensified with the increment of soil contaminant levels. This conclusion is in agreement with the experimental results of Lin et al. (2008), who found the ratio of shoot to root decreased with the increment of soil $\mathrm{Cu}$ contamination levels. In the presence of pyrene, both concentration and accumulation of $\mathrm{Cd}$ in maize tended to decrease with the pyrene contamination. But the interaction between pyrene and $\mathrm{Cd}$ might also be related to the various levels of $\mathrm{Cd}$. In the control soil with 0.13 $\mathrm{mg} \mathrm{Cd} / \mathrm{kg}$ soil, for example, Cd accumulation in maize in the presence of pyrene was not significantly different from that in the absence of pyrene. While in 2.0 and 4.5 $\mathrm{mg} \mathrm{Cd} / \mathrm{kg}$ soil, pyrene contamination significantly decreased both concentration and accumulation of $\mathrm{Cd}$ in maize. It should be mentioned that the contamination of pyrene would cause the decrease of phytoextracting efficiency of Cd in highly Cd polluted soil. This is another important result in this experiment. There can be a competitive adsorption between the co-existence pyrene and cadmium in the maize.

In previous research, it has been shown that maize CT38 (Zea Mays L.) can grow and effectively extract metals in multi-metal (Cu, Cd, $\mathrm{Pb}$ and $\mathrm{Zn}$ ) contaminated soils and vacuolar compartmentalization appeared to be an important source of tolerance of metal-

Table 1: Pyrene contents in the roots and shoots of maize

\begin{tabular}{|c|c|c|c|c|c|}
\hline \multirow{2}{*}{$\begin{array}{c}\text { Treatment } \\
\text { No. }\end{array}$} & \multirow{2}{*}{$\begin{array}{l}\text { Residual pyrene } \\
\text { (mg/kg) }\end{array}$} & \multicolumn{2}{|c|}{$\begin{array}{l}\text { Accumulation concentration } \\
\text { (mg/kg) }\end{array}$} & \multicolumn{2}{|c|}{$\begin{array}{c}\text { Accumulation amount } \\
(\mu \mathrm{g} / \mathrm{pot})\end{array}$} \\
\hline & & Root & Shoot & Root & Shoot \\
\hline A1 & $\mathrm{ND}^{*}$ & $\mathrm{ND}^{*}$ & $0.73 \pm 0.10$ & $\mathrm{ND}^{*}$ & $9.53 \pm 1.77$ \\
\hline A2 & $1.12 \pm 0.13$ & $7.40 \pm 0.44$ & $4.09 \pm 0.39$ & $22.25 \pm 3.11$ & $54.41 \pm 6.18$ \\
\hline A3 & $7.39 \pm 0.72$ & $21.90 \pm 1.50$ & $10.06 \pm 0.86$ & $66.73 \pm 8.12$ & $131.23 \pm 9.29$ \\
\hline A4 & $17.45 \pm 1.20$ & $28.62 \pm 1.86$ & $12.44 \pm 0.94$ & $84.62 \pm 8.04$ & $161.24 \pm 7.15$ \\
\hline B1 & $\mathrm{ND}^{*}$ & $\mathrm{ND}^{*}$ & $0.59 \pm 0.13$ & $\mathrm{ND}^{*}$ & $7.70 \pm 1.18$ \\
\hline B2 & $1.55 \pm 0.27$ & $9.12 \pm 0.62$ & $4.33 \pm 0.31$ & $25.92 \pm 4.57$ & $56.22 \pm 4.67$ \\
\hline B3 & $9.32 \pm 0.78$ & $24.15 \pm 1.77$ & $10.95 \pm 0.70$ & $67.25 \pm 6.66$ & $139.40 \pm 6.79$ \\
\hline B4 & $21.80 \pm 0.78$ & $31.68 \pm 3.11$ & $13.78 \pm 0.94$ & $85.96 \pm 7.06$ & $177.27 \pm 9.08$ \\
\hline B2 & $\mathrm{ND}^{*}$ & $\mathrm{ND}^{*}$ & $0.66 \pm 0.08$ & $\mathrm{ND}^{*}$ & $7.96 \pm 1.23$ \\
\hline $\mathrm{C} 2$ & $1.86 \pm 0.16$ & $10.00 \pm 1.07$ & $5.00 \pm 0.35$ & $25.43 \pm 4.26$ & $61.35 \pm 6.15$ \\
\hline C3 & $10.90 \pm 0.81$ & $27.17 \pm 1.35$ & $12.03 \pm 0.98$ & $69.83 \pm 8.08$ & $147.65 \pm 8.27$ \\
\hline $\mathrm{C} 4$ & $26.38 \pm 2.23$ & $35.14 \pm 2.30$ & $15.73 \pm 0.84$ & $89.06 \pm 9.85$ & $193.07 \pm 9.85$ \\
\hline
\end{tabular}

Values are means \pm S.E.; *ND: not detected 
accumulating plants (Zhou et al., 2005). In greenhouse experiment, it had also been demonstrated that maize CT38 was a promising crop for phytoremediation of co-contaminated soils with cadmium and pyrene. Not only was most pyrene (73\% 88\%) removed from the contaminated soils, but also a small portion of the total cadmium $(0.27 \% \sim 1.41 \%)$ in soils was accumulated by maize. Despite the high concentration of cadmium accumulated in roots, shoot contribute more than $63 \%$ of the accumulation amount of cadmium in plant because of their greater biomass.

\section{CONCLUSION}

Phytoremediation is proposed as one of the in-situ decontamination approaches showing promise for addressing both organic and inorganic contaminants. The present study has demonstrated that the growth response of maize CT38 (Z. mays L.), dissipation of pyrene in soil, uptake and accumulation of pyrene and cadmium by maize might be affected by the cocontamination due to the interaction between heavy metal and organic pollutants. The dissipation of pyrene in both sole and cadmium co-contaminated soil was enhanced by the presence of vegetation. Although the presence of cadmium stimulated the accumulation of pyrene in the roots and shoots of maize, the contribution of plant off-take was less than $0.3 \%$. In contrast, plantpromoted biodegradation was the predominant contribution to the plant-enhanced dissipation of soil pyrene in the cadmium co-contamination. The inhibitory effect of cadmium on the dissipation of pyrene increased with the Cd load, which suggested that the change in microbial activity or plant root physiology under cadmium stress was not beneficial to the dissipation of pyrene. Plant root exudates appear to promote the number of rhizosphere microorganisms and enzyme activity, thereby improving degradation. It was observed that maize removed about on the average $0.70 \%$ of the total cadmium amount in soil by plant uptake, but the ability of Cd phytoextraction would be inhibited under co-contaminated of pyrene. Maize CT38 can normally grow in the co-contaminated soil with hige level $\mathrm{Cd}$ and pyrene and can effectively remedy the sites cocontaminated with these two types of contamination, which suggesting the possibility of phytoremediating two different contaminant types simultaneously. These findings provide preliminary evidence for the potential of maize CT38 in the remediation of pyrene-cadmium co-contaminated soil.

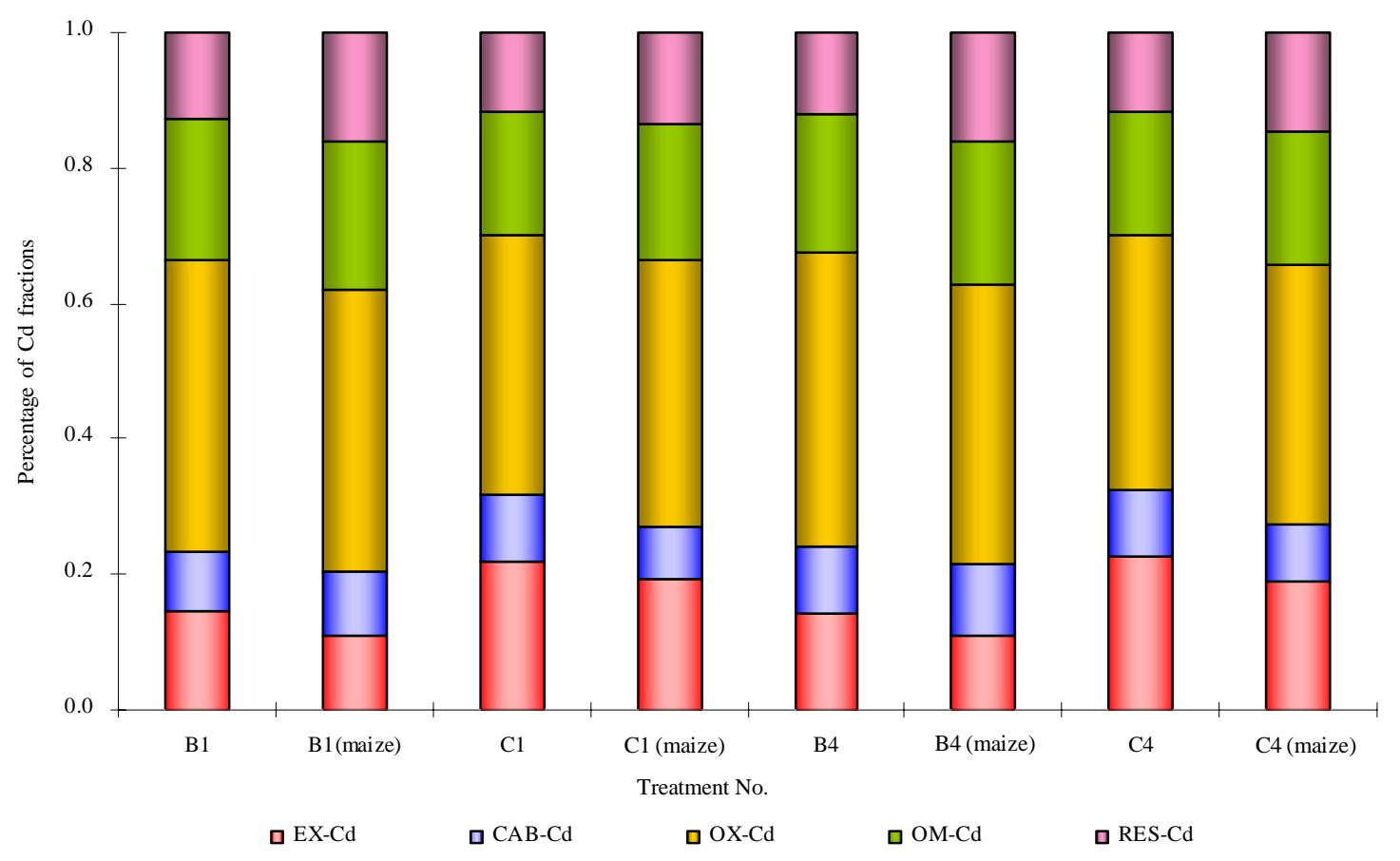

Fig. 4: Fraction of Cd in unplanted and planted soil 
Int. J. Environ. Sci. Tech., 6 (2), 249-258, Spring 2009

Table 2: Cd concentration and accumulation in maize after 60 days culture

\begin{tabular}{|c|c|c|c|c|c|c|c|}
\hline \multicolumn{2}{|c|}{$\begin{array}{c}\text { Concentration added } \\
(\mathrm{mg} / \mathrm{kg})\end{array}$} & \multicolumn{2}{|c|}{$\begin{array}{l}\text { Concentration of Cd in maize } \\
(\mathrm{mg} / \mathrm{kg})\end{array}$} & \multirow[t]{2}{*}{$\mathrm{S} / \mathrm{R}^{\mathrm{a}}$} & \multicolumn{2}{|c|}{$\begin{array}{l}\text { Accumulation of Cd in maize } \\
\text { ( } \mu \mathrm{g} / \mathrm{pot})\end{array}$} & \multirow[t]{2}{*}{$\begin{array}{c}\text { Soil purifying rate } \\
(\%)\end{array}$} \\
\hline $\mathrm{Cd}$ & Pyrene & Root & Shoot & & Root & Shoot & \\
\hline 0 & 0 & $0.75 \mathrm{a}$ & $0.38 \mathrm{a}$ & 0.50 & $2.34 \mathrm{a}$ & $4.87 \mathrm{a}$ & 1.41 \\
\hline 0 & 10 & $0.64 \mathrm{a}$ & $0.33 \mathrm{a}$ & 0.52 & $1.90 \mathrm{a}$ & $4.29 \mathrm{a}$ & 1.22 \\
\hline 0 & 50 & $0.70 \mathrm{a}$ & $0.35 \mathrm{a}$ & 0.49 & $2.12 \mathrm{a}$ & $4.55 \mathrm{a}$ & 1.31 \\
\hline 0 & 100 & $0.62 \mathrm{a}$ & $0.29 \mathrm{a}$ & 0.47 & $1.86 \mathrm{a}$ & $3.81 \mathrm{a}$ & 1.11 \\
\hline 2.0 & 0 & 5.49 bc & 1.93 bc & 0.35 & $15.69 \mathrm{c}$ & 25.00 bc & 0.53 \\
\hline 2.0 & 10 & $6.32 \mathrm{~cd}$ & 2.26 cde & 0.36 & $17.72 \mathrm{~d}$ & 29.51 cde & 0.62 \\
\hline 2.0 & 50 & $5.13 \mathrm{~b}$ & $1.75 \mathrm{~b}$ & 0.34 & 14.31 bc & $22.54 \mathrm{~b}$ & 0.49 \\
\hline 2.0 & 100 & $4.68 \mathrm{~b}$ & $1.73 \mathrm{~b}$ & 0.37 & $12.70 \mathrm{~b}$ & $22.39 \mathrm{~b}$ & 0.46 \\
\hline 4.5 & 0 & $8.89 \mathrm{f}$ & $2.86 \mathrm{f}$ & 0.32 & $22.76 \mathrm{f}$ & $34.77 \mathrm{e}$ & 0.34 \\
\hline 4.5 & 10 & 8.43 ef & $2.53 \mathrm{ef}$ & 0.30 & 21.32 ef & 31.08 de & 0.32 \\
\hline 4.5 & 50 & $7.69 \mathrm{e}$ & $2.28 \mathrm{de}$ & 0.30 & $19.65 \mathrm{e}$ & $28.16 \mathrm{~cd}$ & 0.29 \\
\hline 4.5 & 100 & $6.72 \mathrm{~d}$ & $2.11 \mathrm{~cd}$ & 0.31 & $17.66 \mathrm{~d}$ & $26.07 \mathrm{bcd}$ & 0.27 \\
\hline
\end{tabular}

shoot/root ratio of cadmium concentration

\section{ACKNOWLEDGMENTS}

This work was funded as part of a key project of National Natural Science Foundation of China (40730741), Open Foundation of State Key Laboratory of environmental geochemistry of China, Application and demonstration project of Guangzhou Environmental Protection Bureau scientific and technology achievements of China. The authors thank Professor James Irish at South China University of Technology for editing the manuscript.

\section{REFERENCES}

Baker, A. J. M.; McGrath, S. P.; Sidoli, C. M. D.; Reeves, R. D., (1994). The possibility of in situ heavy metal decontamination of polluted soils using crops of metalaccumulating plants. Resour. Conserv. Recy., 11 (1-4), 4149 (9 pages).

Benin, A. L.; Sargent, J. D.; Dalton; M.; Roda, S., (1999). High concentrations of heavy metals in neighborhoods near ore smelters in northern Mexico. Environ. Health Persp., 107 (4), 279-284 (6 pages).

Blaylock, M.; Salt, D. E.; Dushenkov, S.; Zakharova, O.; Kapulnik, Y.; Ensley, B. D, (1997). Enhanced accumulation of $\mathrm{Pb}$ in Indian mustard by soil-applied chelating agents. Environ. Sci. Tech. 31 (3), 860-865 (6 pages).

Chekol, T.; Vough, L. R.; Chaney, R. L., (2004). Phytoremediation of polychlorinated biphenylcontaminated soils: The rhizosphere effect. Environ. Int., 30 (6), $799-804$ (6 pages).

Cheng, S. P., (2003). Heavy metal pollution in China: Origin, pattern, and control. Environ. Sci. Pollut. Res., 10 (3), 192-198 (7 pages).

Gao, Y. Z.; Zhu, L. Z., (2004). Plant uptake, accumulation and translocation of phenanthrene and pyrene in soils. Chemosphere, 55 (9), 1169-1178 (19 pages).

Garbisu, C.; Alkorta, I., (2001). Phytoextraction: A costeffective plant-based technology for the removal of metals from the environment. Biores. Tech., 77 (3), 229-236 (8 pages).
He, Y.; Xu, J. M.; Tang, C. X.; Wu, Y. P., (2005). Facilitation of pentachlorophenol degradation in the rhizophere of ryegrass (Loium perenne L.). Soil Biol. Biochem., 37 (11), 2017-2024 (8 pages).

Kaimi, E.; Mukaidani, T.; Miyoshi, S.; Tamaki, M., (2006). Ryegrass enhancement of biodegradation in dieselcontaminated soil. Environ. Exp. Bot., 55 (1-2), 110-119 (10 pages).

Kipopoulou, A. M.; Manoli, E.; Samara, C., (1999). Bioconcentration of PAHs in vegetables grown in an industrial area. Environ. Pollut., 106 (3), 369-380 (12 pages).

Kuo, C. W.; Genthner, B. R. S., (1996). Effect of added heavy metal ions on biotransformation and biodegradation of 2chlorophenol and 3-chlorobenzoate in anaerobic bacterial consortia. Appl. Environ. Microbiol., 62 (7), 2317-2323 (7 pages).

Lin, Q.; Wang, Z. W.; Ma, S.; Cheng, Y. X., (2006). Evaluation of dissipation mechanisms by Lolium perenne $\mathrm{L}$. and Raphanus sativus for pentachlorophenol (PCP) in copper co-contaminated soil. Sci. Total Environ., 368 (2-3), 814822 (9 pages).

Lin, Q.; Shen, K. L.; Zhao, H. M.; Li, W. H., (2008). Growth response of Zea mays L. in pyrene-copper co-contaminated soil and the fate of pollutants. J. Hazard. Mater., 150 (3), 515-521 (7 pages).

Ling, W. T.; Gao, Y. Z., (2004). Pomoted dissipation of phenanthrene and pyrene in soils by amaranth (Amaranthus tricolor L.). Environ. Geol., 46 (5), 553-560 (8 pages).

Liste, H. H.; Alexander, M., (2000). Accumulation of phenanthrene and pyrene in rhizosphere soil. Chemosphere, 40 (1), 11-14 (4 pages).

Lovley, D. R.; Coates, J. D., (1997). Bioremediation of metal contamination. Curr. Opin. Biotech., 8 (3), 285-289 (5 pages).

Maslin, P.; Maier, R. M., (2000). Rhamnolipid-enhanced mineralization of phenanthrene in organic-metal cocontaminated soils. Bioremediat, J., 4 (4), 295-308 (14 pages).

McGrath, S. P.; Zhao, F. J.; Lombi, E., (2001). Plant and rhizosphere processes involved in phytoremediation of metal contaminated soils., Plant Soil, 232 (1-2), 207-214 
(8 pages).

McIntyre, T.; Glennis, M. L., (1997). The advancement of phytoremediation as an innovative environmental technology for stabilization, remediation or restoration of contaminated sites in Canada: A discussion paper. J. Soil Contam., 6 (3), 227-241 (15 pages)

Nakamura, T.; Motoyama, T.; Suzuki, Y.; Yamaguchi, I., (2004). Biotransformation of pentachlorophenol by Chinese chive and a recombinant derivative of its rhizospherecompetent microorganism, Pseudomonas gladioli M-2196. Soil Biol. Biochem., 36 (5), 787-795 (9 pages).

Olson, P. E.; Wong, T.; Leigh, M. B.; Fletcher, J. S., (2003). Allometric modeling of plant root growth and its application in rhizosphere remediation of soil contaminants. Environ. Sci. Tech., 37 (3), 638-643 (6 pages).

Pascale, M; Raina, M. M., (2000). Rhamnolipid-enhanced mineralization of phenantheren in organic-metal cocontaminated soils. Bioremediat. J., 4 (4), 295-308 (14 pages).

Polder, M. D.; Hulzebos, E. M.; Jager, D. T., (1995). Validation of models on uptake of organic chemicals by plant roots. Environ. Toxicol. Chem., 14 (9), 1615-1623 (9 pages).

Said, W. A.; Lewis, D. L., (1991). Quantitative assessment of the effects of metals on microbial degradation of organic chemicals. Appl. Environ. Microbiol., 57 (5), 1498-1503 (6 pages).

Sandrin, T. R.; Maier, R. M., (2002). Effect of pH on cadmium toxicity, speciation, and accumulation during naphthalene biodegradation. Environ. Toxicol. Chem., 21 (10), 20752079 (5 pages)

Schnoor, J. L.; Licht, L. A.; McCutcheon, S. C.; Wolfe, N. L.; Carreira, L. H., (1995). Phytoremediation of organic and nutrient contaminants. Environ. Sci. Tech., 29 (7), 318323 (6 pages).

Schroll, R.; Bierling, B.; Cao, G.; Dorfler, U.; Lahaniati, M.; Langenbach, T.; Scheunert, I.; Winkler, R., (1994). Uptake pathways of organic chemicals from soil by agricultural plants. Chemosphere, 28 (2), 297-303 (7 pages).

Tessier, A.; Campbell, P. G. C.; Bisson, M., (1979). Sequential extraction procedure for the speciation of particulate trace metals. Anal. Chem., 51 (7), 844-850 (7 pages).

Trapp, S.; Matthies, M.; Scheunert, I.; Topp, E. M., (1990). Modeling the bioconcentration of organic chemicals in plants. Environ. Sci. Tech., 24 (8), 1246-1252 (7 pages).

Zhang, H.; Dang, Z.; Yao, L. X., (2007). Eco-toxicologic effect of cadmium and pyrene combined and simplex pollution on soil microbe. J. Agro. Environ. Sci., 26 (6), 2225-2230 (6 pages).

Zhou, J. M.; Dang, Z.; Tao, X. Q.; Zhou, Y. Z., (2005). Influence of NTA on accumulation and subcellular distribution of copper and zinc in corn (Zea mays). Environ. Sci., 26 (6), 127-131 (5 pages).

Zhou, J. M.; Dang, Z.; Cai, M. F., (2007). Soil heavy metal pollution around the Dabaoshan mine, Guangdong province, China. Pedosphere, 17 (5), 588-594 (7 pages).

\section{AUTHOR (S) BIOSKETCHES}

Zhang, H., Ph.D. research student of environmental science and engineering, School of Environmental Science and Engineering, South China University of Technology, Guangzhou Higher Education Mega Center, Guangzhou 510006, P.R. China. Email: hui.zh@mail.scut.edu.cn

Dang, Z., Ph.D., Full professor of environmental chemistry, Head of school, Environmental Science and Engineering, South China University of Technology, Guangzhou Higher Education Mega Center, Guangzhou 510006, P.R. China. Email: chzdang@scut.edu.cn

Zheng, L. C., Ph.D. research student of environmental science and engineering, School of Environmental Science and Engineering, South China University of Technology, Guangzhou Higher Education Mega Center, Guangzhou 510006, P.R. China. Email: zlc1982@sina.com

Yi, X. Y., Ph.D., Associated professor of environmental chemistry, School of Environmental Science and Engineering, South China University of Technology, Guangzhou Higher Education Mega Center, Guangzhou 510006, P.R. China. Email: xxyi@scut.edu.cn

\section{This article should be referenced as follows:}

Zhang, H.; Dang, Z.; Zheng, L. C.; Yi, X. Y., (2009). Remediation of soil co-contaminated with pyrene and cadmium by growing maize (Zea mays L.). Int. J. Environ. Sci. Tech., 6 (2), 249-258. 